\title{
Pelvic organ prolapse and collagen-associated disorders
}

\author{
Karin Lammers • Sabrina L. Lince • Marian A. Spath • \\ Léon C. L. T. van Kempen • Jan C. M. Hendriks • \\ Mark E. Vierhout $\cdot$ Kirsten B. Kluivers
}

Received: 29 March 2011 / Accepted: 21 July 2011 /Published online: 3 August 2011

(C) The Author(s) 2011. This article is published with open access at Springerlink.com

\begin{abstract}
Introduction and hypothesis Pelvic organ prolapse (POP) and other disorders, such as varicose veins and joint hypermobility, have been associated with changes in collagen strength and metabolism. We hypothesized that these various disorders were more prevalent in both POP patients and their family members.

Methods In this study, the prevalence of various collagenassociated disorders, including POP, was compared between POP patients $(n=110)$ and control patients $(n=100)$ and their first and second degree family members.

Results POP patients reported a higher prevalence of varicose veins, joint hypermobility and rectal prolapse and were more likely to have family members with POP as compared to the control group $(p<0.01)$. In contrast, the family members of the POP group did not report a higher prevalence of collagen-associated disorders compared to the family members of the control group $(p=0.82)$.
\end{abstract}

K. Lammers $(\bowtie) \cdot$ S. L. Lince $\cdot$ M. A. Spath $\cdot$ M. E. Vierhout

K. B. Kluivers

Department of Obstetrics and Gynaecology (791),

Radboud University Nijmegen Medical Centre,

P.O. Box 9101, 6500 HB Nijmegen, The Netherlands

e-mail: K.Lammers@obgyn.umcn.nl

L. C. L. T. van Kempen

Department of Pathology, McGill University,

Montreal, Canada

L. C. L. T. van Kempen

Lady Davis Institute for Medical Research,

Jewish General Hospital,

Montreal, Canada

J. C. M. Hendriks

Department of Biostatistics, Epidemiology and HTA,

Radboud University Nijmegen Medical Centre,

Nijmegen, The Netherlands
Conclusions POP and other collagen-associated disorders may have a common aetiology, originating at the molecular level of the collagens.

Keywords Pelvic organ prolapse - Collagen · Heredity · Varicose veins $\cdot$ Rectal prolapse $\cdot$ Joint hypermobility

$\begin{array}{ll}\text { Abbreviations } \\ \text { POP } & \text { Pelvic organ prolapse } \\ \text { EDS } & \text { Ehlers-Danlos syndrome } \\ \text { AAA } & \text { Abdominal aorta aneurysm } \\ \text { POP-Q } & \text { Pelvic organ prolapse quantification } \\ \text { POF } & \text { Premature ovarian failure } \\ \text { BMI } & \text { Body mass index }\end{array}$

\section{Introduction}

Pelvic organ prolapse (POP) is a common condition among adult vaginally parous women of all ages, with reported prevalence numbers up to $37 \%$ [1]. It has previously been stated that an alteration in collagen metabolism is relevant in the aetiology of POP. Jackson et al. have formulated this finding in 1996, and it has been supported since [2, 3].

Collagen is a fibrous protein and the main component of connective tissue. It provides tensile strength to skin, tendons and bones [2]. In the 1930s, the first evidence for a regular structure of collagen molecules was found, and so far, more than 20 subtypes have been identified. Types I, III and $\mathrm{V}$ are the principal components to provide strength to soft tissues. Collagen type I is non-elastic and confers great resistance to tensile forces, whereas collagen type III has elastic properties and is prevailing in more flexible tissues. Both type I and III collagens are present in granulation 
tissue during wound repair [3]. Type $\mathrm{V}$ collagen is a quantitatively minor fibrillar collagen, but it is widely distributed in a variety of tissues [4]. An increase in collagen type III and V is associated with a decrease in mechanical strength of connective tissue due to decreased fibre size. It is generally agreed that a higher I to III ratio in tissues is indicative of greater strength, whereas a lower ratio may result in tissue laxity [3]. Collagen-associated disorders may arise from genetic defects, which can affect any step in the normal collagen production.

The most eminent inherited collagen-associated disorder is the Ehlers-Danlos syndrome (EDS). This syndrome consists of a heterogeneous group of clinical features caused by underlying defects in the collagen type I, III and $\mathrm{V}$ gene as well as defects in proteins important for the post-translational modifications and processing of these collagens [5]. It is known that female patients with EDS have a higher risk of developing POP [6]. Besides, both male and female patients with one of the different subtypes of EDS reported a higher prevalence of joint hypermobility; arterial rupture; rupture of diaphragm; atrophic scarring; varicose veins; cardiac valvular disease, such as cardiac valve prolapse; rectal prolapse and inguinal, umbilical or other hernias [5]. Other investigators have focused on these different diseases in the general population and their relation to collagen. They found changes in collagen quantity or composition of the different collagen subtypes in for example patients with POP [2, 3], inguinal hernia [710], varicose veins [11-13], arterial aneurysm [14] and joint hypermobility [15]. This suggests a common pathophysiologic pathway for both POP and the above-mentioned disorders.

If changes in collagen are an underlying cause of all these disorders, one would expect that they coexist in the same patient. Moreover, if these collagen changes are based on genetic defects, family members of these patients are expected to be affected more often. Miedel et al. have found that a history of conditions suggestive of deficient connective tissues, such as varicose veins, hernia and hemorrhoid, was significantly associated with symptomatic POP in these women [16]. Furthermore, it has been reported that patients with abdominal aorta aneurysm are at higher risk for inguinal hernia repair and abdominal wall hernias $[17,18]$ and that POP patients more often report joint laxity [19-21]. Until now however, it is not known whether the incidence of these collagen-associated disorders is higher in families of women with POP, which would be expected in case of inheritable collagen disorders.

The aim of this study was to assess the association between POP and other collagen-associated disorders. We hypothesized that POP patients more often have concomitant collagen-associated disorders as compared to controls. Furthermore, we hypothesized that these various disorders, including POP, are more prevalent in the genetically related first and second degree family members of POP patients than in family members of controls.

\section{Materials and methods}

An observational cohort study was conducted among consecutive gynaecological patients between January 2007 and August 2010 at the Department of Obstetrics and Gynaecology of the Radboud University Nijmegen Medical Centre, the Netherlands. During the study period, all these patients underwent gynaecological examination and they completed a questionnaire on parity and hormonal status, smoking habits, weight, height and medical and surgical history. Besides, information on POP in their first and second degree female family members was obtained. Additionally, detailed questions on the presence of conditions suggestive of deficient connective tissue in the patients and their family members were completed by the patients presenting at our department between January 2009 and August 2010.

Data were also used from women previously included in another study protocol, in which female family members were elaborately interviewed on their medical history, including specific questions on gynaecological history. Data were collected either by telephone interview or by written questionnaire. The primary outcome of that study was the prevalence of premature ovarian failure (POF, i.e. amenorrhea before age of 40 years) in families with a patient with Fragile X syndrome [22]. These women did not undergo gynaecological examination at our department.

All our gynaecological patients as well as the first female family member of the families that were interviewed for the POF study are subsequently referred to as index cases.

Index cases were considered a "POP index case" if they had clinical signs of POP on gynaecological examination (POP-Q stage two or higher) [23] and/or had undergone POP surgery in the past. Women who were not examined at our department, but who had undergone POP operation(s) previously or were diagnosed with POP by a medical professional, were also included in this group.

Women were classified as being a "control index case" if they had no signs and symptoms of POP, at the time of the study or in the past. Female family members were considered as having POP if they had undergone POP operation(s) previously or were diagnosed with POP by a medical professional.

Index cases and first and second degree family members, both male and female, were considered as having a collagen-associated disorder if they had a history of one or more of the following diseases: arterial aneurysm, inguinal hernia, cardiac valve prolapse, varicose veins, 
intervertebral disc displacement (i.e. nucleus pulposus hernia), umbilical hernia, joint hypermobility and rectal prolapse. Joint hypermobility was considered present if a person responded positive on the question if they had ever had a luxation or sprain of a joint. Subsequently, these eight disorders are referred to as the collagen-associated disorders. Two disorders were assessed separately with one being fascia wound dehiscence and the other diaphragmatic hernia. Fascia wound dehiscence was mentioned separately because to develop this disorder, one had to have undergone abdominal surgery and furthermore, fascia wound dehiscence could be the result of operation technique. Diaphragmatic hernia was assessed separately because this might be the result of an embryologic development disorder which does not necessarily reflect a collagen-associated disorder as such and moreover, this disorder might be present without the patient knowing.

Both POP and control index cases had to fulfill two inclusion criteria: because POP in general develops later in life, all index cases had to be 50 years or older at the time of participation. Since vaginal delivery is regarded as the major risk factor for the development of POP, all index cases had to be vaginally parous as well. Exclusion criteria for all index cases were the presence of genetic diseases with a known increased risk of POP, such as Ehlers-Danlos syndrome, and furthermore, inadequate comprehension of the Dutch language.

The study protocol was approved by the institutional research ethics committee under number CMO 2007/043 and informed consent was obtained from all participants.

\section{Statistical methods}

The Kruskal-Wallis test was used to test differences between the two groups for statistical significance in case of continuous variables and the Fisher's exact test was used in case of $2 \times 2$ tables. Multivariate logistic regression was used to study possible confounders in the relation between presence of collagen-associated disorders and POP, using the index cases only. The dependent variable was presence of collagen-associated disorders. Confounders of interest in this study were: parity, BMI, smoking, menopause and pulmonary disease. Analyses were performed using SPSS 16.0 (Chicago, IL, USA) for Windows. $p$ values below .05 were considered statistical significant.

\section{Results}

A total of 237 women met the inclusion criteria for index case. Of these, 165 were included during routine clinical practise and 72 were from the study on POF. Twenty-seven medical records did not include information on collagen- associated disorders in either the patient or her family members, neither was there information available on the prevalence of POP in female family members and we were not able to obtain this information otherwise. These women were therefore excluded from analyses. Thus, 110 POP index cases and 100 control index cases were included in this study.

Figure 1 shows a flowchart of the study. The POP and control index cases are subdivided according to inclusion during routine clinical practise and inclusion from the POF study.

Table 1 shows the number of families of POP and control index cases by their number of siblings and their number of children. POP index cases had in $78 \%$ of the cases "average" sized families with 54 women having two children and 32 women having three children $((54+32) /$ $110=78 \%)$, compared to $67 \%$ in control index cases ( $(38+$ 29)/100). Control index cases more often had larger families ( $\geq 5$ children) compared to POP index cases $(17 \%$ $(17 / 100)$ and $5 \%(6 / 110)$, respectively). On average, the number of siblings was the same between both groups even though $7 \%(8 / 110)$ of POP index cases had two siblings compared to $17 \%(17 / 100)$ of control index cases. Consequently, more POP index cases had $\geq 5$ siblings compared to control index cases, $45 \%(49 / 110)$ and $32 \%$ (32/100), respectively.

Table 2 outlines the baseline characteristics of the index cases as well as the number of collagen-associated disorders in both POP and control index cases and in their first and second degree family members. Both groups of index cases were comparable with regard to age, BMI, menopause and pulmonary disease. There was a statistical significant difference between both groups regarding number of

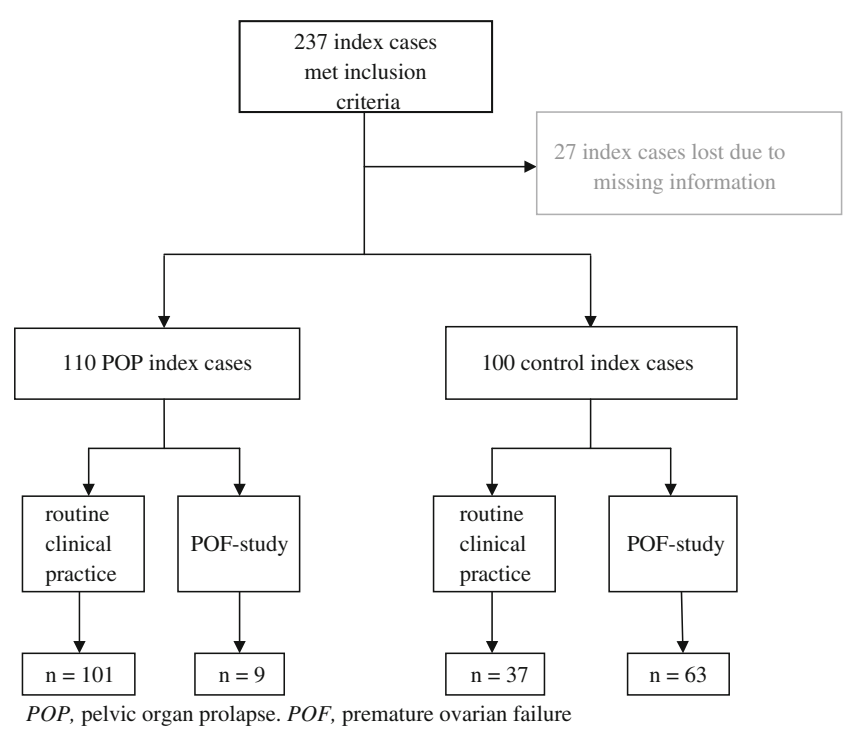

Fig. 1 Flowchart of index cases included in the study 
Table 1 Size and structure of families of POP and control index cases

$P O P$ pelvic organ prolapse

\begin{tabular}{|c|c|c|c|c|c|c|c|c|}
\hline \multirow[t]{2}{*}{ Number of children } & \multicolumn{8}{|c|}{ Number of siblings } \\
\hline & 0 & 1 & 2 & 3 & 4 & $\geq 5$ & Unknown & Total \\
\hline \multicolumn{9}{|l|}{ POP } \\
\hline 0 & - & - & - & - & - & - & - & - \\
\hline 1 & - & 3 & 1 & 1 & 3 & 3 & 2 & 13 \\
\hline 2 & 1 & 3 & 5 & 11 & 5 & 21 & 8 & 54 \\
\hline 3 & - & 3 & 1 & 2 & 3 & 19 & 4 & 32 \\
\hline 4 & - & - & - & 1 & 1 & 3 & - & 5 \\
\hline$\geq 5$ & - & - & 1 & 1 & 1 & 3 & - & 6 \\
\hline Total & 1 & 9 & 8 & 16 & 13 & 49 & 14 & 110 \\
\hline \multicolumn{9}{|l|}{ Control } \\
\hline 0 & - & - & - & - & - & - & - & - \\
\hline 1 & 1 & - & 2 & 3 & - & 3 & 1 & 10 \\
\hline 2 & 1 & 2 & 7 & 1 & 9 & 12 & 6 & 38 \\
\hline 3 & - & 3 & 5 & 5 & 1 & 11 & 4 & 29 \\
\hline 4 & - & 1 & 1 & 1 & 1 & 2 & - & 6 \\
\hline$\geq 5$ & - & 1 & 2 & 3 & 3 & 4 & 4 & 17 \\
\hline Total & 2 & 7 & 17 & 13 & 14 & 32 & 15 & 100 \\
\hline
\end{tabular}

children and smoking ( $p=0.03$ and $p=0.02$, respectively). Varicose veins, hypermobility and rectal prolapse were significantly more often reported by POP index cases $(p<$ 0.01). Regarding the presence of at least one collagenassociated disorder, a statistical significant difference was found between both groups $(p<0.01)$, with collagenassociated disorders being more prevalent in the group of POP index cases. Using logistic regression, the relation between POP and collagen-associated disorders was similar after correction for parity and smoking.

Mothers of POP index cases were nearly four times more likely to have (had) POP themselves as compared to mothers of control index cases $(p<0.01)$ whereas sisters of POP index cases were nearly nine times more likely to have (had) POP compared to sisters of control index cases $(p<0.01)$.

A minimal larger percentage of family members of POP index cases was affected by a collagen-associated disorder. Nineteen percent (12/63) of POP index cases had a family member that was affected, while this accounted for $14 \%$ $(12 / 84)$ of the control index cases. This difference was not statistically significant $(p=0.82)$.

\section{Discussion}

In this observational cohort study, we assessed whether the prevalence of collagen-associated disorders was higher among women with POP and among their first and second degree family members compared to controls and their families. The presence of a collagen-associated disorder, independent of the number of reported collagen-associated disorders, was statistically significant higher in the POP index cases as compared to controls. Varicose veins, joint hypermobility and rectal prolapse were each significantly more prevalent in the POP index cases. With regard to the families of the index cases, a higher prevalence of POP among female family members of POP index cases was found. With our data, we were not able to identify a difference between both groups regarding the prevalence of collagen-associated disorders in first and second degree family members. To our best knowledge, no previous study has assessed the combination of these various collagenassociated disorders together, in relation to POP.

Our study revealed that mothers and sisters of POP index cases were respectively nearly four and nine times more likely to report POP as compared to mothers and sisters of control index cases. This is in line with findings of previous studies that reported a higher risk of POP in women with mothers or sisters reporting POP [24-28]. Even though the aetiology of POP is complex, it is recognized to be multifactorial in its origin with an eminent contribution of genetics. A large twin study showed that heritability contributes significantly to the occurrence of POP [29]. These observations support the hypothesis that a genetic predisposition to the condition exists and therefore we expected more collagen-associated disorders in women with POP and their first and second degree family members.

Prevalence of POP is significantly correlated with the occurrence of a collagen-associated disorder. The presence of either varicose veins, joint hypermobility or rectal prolapse is individually correlated to the presence of POP. The finding that a higher prevalence of varicose veins 
Table 2 Characteristics and disorders of POP and control index cases and their first and second degree family members

\begin{tabular}{|c|c|c|c|c|c|}
\hline Index cases & POP total & $n(\%)$ or median [range] & Control total & $n(\%)$ or median [range] & $p$ value \\
\hline Age [years] & 110 & 63 [51-89] & 100 & $64[51-95]$ & 0.37 \\
\hline Children [number] & 110 & $2[1-11]$ & 100 & $3[1-10]$ & 0.03 \\
\hline BMI $\left[\mathrm{kg} / \mathrm{m}^{2}\right]$ & 84 & $25[17-41]$ & 90 & $25[19-42]$ & 0.33 \\
\hline Smoking $^{\mathrm{a}}$ & 65 & $21(32)$ & 83 & $38(46)$ & 0.02 \\
\hline Menopause $^{\mathrm{b}}$ & 93 & $89(96)$ & 94 & $89(95)$ & 0.14 \\
\hline Pulmonary disease ${ }^{c}$ & 54 & $7(13)$ & 84 & $9(11)$ & 0.09 \\
\hline \multicolumn{6}{|l|}{ Collagen-associated disorders ${ }^{\mathrm{d}}$} \\
\hline - AAA & 59 & $0(0)$ & 84 & $1(1)$ & 1.00 \\
\hline - Inguinal hernia & 55 & $0(0)$ & 84 & $0(0)$ & 1.00 \\
\hline - Cardiac valve prolapse & 58 & $0(0)$ & 84 & $2(2)$ & 0.51 \\
\hline - Varicose veins & 55 & $15(27)$ & 84 & $5(6)$ & $<0.01$ \\
\hline - Intervertebral disc displacement & 53 & $5(9)$ & 84 & $8(10)$ & 1.00 \\
\hline - Umbilical hernia & 53 & $3(6)$ & 84 & $2(2)$ & 0.38 \\
\hline - Joint hypermobility & 63 & $12(19)$ & 82 & $2(2)$ & $<0.01$ \\
\hline - Rectal prolapse & 53 & $13(25)$ & 84 & $0(0)$ & $<0.01$ \\
\hline Presence of collagen-associated disorder ${ }^{\mathrm{b}}$ & 63 & $31(49)$ & 84 & $18(21)$ & $<0.01$ \\
\hline Fascia wound dehiscence & 53 & $2(4)$ & 84 & $1(1)$ & 0.56 \\
\hline Diaphragmatic hernia & 52 & $1(2)$ & 84 & $1(1)$ & 1.00 \\
\hline \multicolumn{6}{|l|}{ First and second degree family members } \\
\hline \multicolumn{6}{|l|}{ Prolapse } \\
\hline - Mother & 110 & $77(70)$ & 100 & $20(20)$ & $<0.01$ \\
\hline - Sisters & 231 & $78(34)$ & 166 & $6(4)$ & $<0.01$ \\
\hline \multicolumn{6}{|l|}{ Collagen-associated disorders ${ }^{\mathrm{d}}$} \\
\hline - AAA & 59 & $1(2)$ & 84 & $1(1)$ & 1.00 \\
\hline - Inguinal hernia & 55 & $7(13)$ & 84 & $1(1)$ & 0.62 \\
\hline - Cardiac valve prolapse & 58 & $0(0)$ & 84 & $2(2)$ & 0.23 \\
\hline - Varicose veins & 55 & $5(9)$ & 84 & $8(10)$ & 0.53 \\
\hline - Intervertebral disc displacement & 53 & $9(17)$ & 84 & $8(10)$ & 0.78 \\
\hline - Umbilical hernia & 53 & $0(0)$ & 84 & $1(1)$ & 0.48 \\
\hline - Joint hypermobility & 63 & $0(0)$ & 82 & $2(2)$ & 0.23 \\
\hline - Rectal prolapse & 53 & $0(0)$ & 84 & $0(0)$ & 1.00 \\
\hline Presence of collagen-associated disorder ${ }^{\mathrm{e}}$ & 63 & $12(19)$ & 84 & $12(14)$ & 0.82 \\
\hline Fascia wound dehiscence & 53 & $0(0)$ & 84 & $0(0)$ & 1.00 \\
\hline Diaphragmatic hernia & 52 & $1(2)$ & 84 & $2(2)$ & 0.61 \\
\hline
\end{tabular}

$p$ value for difference between POP and control groups using Fisher's Exact test except for patient characteristics for which Kruskal-Wallis test was used

$P O P$ pelvic organ prolapse, $B M I$ body mass index, $A A A$ abdominal aorta aneurysm

${ }^{a}$ Including former smokers

${ }^{\mathrm{b}}$ Including post-menopausal women using hormone replacement therapy

${ }^{\mathrm{c}}$ Including asthma, chronic obstructive pulmonary disease, bronchitis and other pulmonary diseases

${ }^{\mathrm{d}}$ Multiple diagnoses per person possible

${ }^{\mathrm{e}}$ At least one of the collagen-associated disorders mentioned above

amongst POP index cases as compared to controls is in agreement with observations of Miedel et al. [16] Furthermore, we confirm the previously reported association between self-reported joint hypermobility and POP [1921, 30]. The study of Hansell et al. showed that the influence of common genes may underlie the association between elbow mobility and POP [31]. Furthermore, Knuuti et al. found that women with joint hypermobility and recurrence of POP have significantly high concentrations of type III collagen [32]. Together with our findings, it seems likely that a common defect affecting collagen strength or metabolism is responsible for these two 
disorders. Whether this is also the case for rectal prolapse, the third collagen-associated disorder individually more frequent observed in POP patients, will need to be confirmed in additional studies. From a clinical point of view, other risk factors such as chronic constipation, excessive straining, and age might be a major risk factor for rectal prolapse, although the higher prevalence of rectal prolapse in EDS patients makes a genetic susceptibility likely as well. The underlying cause is most likely a combination of both genetic and non-genetic risk factors.

Collagen-associated disorders in relation to POP are still poorly understood. Until now, connective tissues have been assessed through biochemical evaluation of the collagen metabolism in the local tissues, and only few genetic polymorphisms have been studied [33, 34]. The available data on the changes in local collagen metabolism are often conflicting. Most recent studies found a decrease in collagen I to III ratio and a higher level of collagen type III in both POP and other collagen-associated disorders. A recent study by Haviarova et al., for example, reported a lower collagen I to III ratio and significantly more collagen type III in varicose vein walls [11]. This was, however, in contrast with a previous report on down-regulated collagen type III and a significantly higher level of collagen I, resulting in an increased collagen I to III ratio [12]. Strengthened by our present findings, we speculate that the common denominator is a change in collagen strength originating from a genetic defect. Due to stretch and repair, the disorder itself may then lead to an alteration in the local collagen metabolism. Detailed assessment of changes on a molecular level and the effects on collagen turn-over and tensile strength in relation to POP is needed to unveil a possible common molecular basis of collagen-associated disorders arising in POP patients.

Although the large sample size is a clear strength of the present study, we are aware of some limitations. We have included index cases from two populations. Both provided us with valuable information, but had their own limitations. In one population, the index cases have undergone gynaecological examination to assess for signs of POP and completed a questionnaire on their own and family members' medical history. In these women, we were not able to interview the family members directly. Their medical information was obtained through the index cases, which may lead to underreporting of the disorders. For future research, a questionnaire or telephone interview addressing all family members, might meet these objections. In the other population that we included in this study, we were able to interview all individual female family members, but we were limited by the fact that no gynaecological examination was available in these women.

There is no known association between POP and the presence of Fragile $\mathrm{X}$ syndrome or a premuation for this syndrome. Therefore, we considered the risk to develop POP to be equal for all women included in our study.

In the baseline characteristics, our control index cases had a statistically significant higher number of children and they were more likely to smoke or to have smoked in the past, as compared to the POP index cases. The difference in parity and smoking between both groups was not considered a confounder in this study, since the relation between POP and collagen-associated disorders remained the same after applying multivariate logistic regression.

In conclusion, our study shows that women with POP are more likely to have first and second degree family members with the same condition. POP index cases are more likely to have a collagen-associated disorder. Furthermore, when assessing varicose veins, joint hypermobility and rectal prolapse individually, these conditions are more common amongst women with POP. A common aetiology of these disorders, originating at the genetic level of collagen, seems likely. In this study, however, this relation was confined to POP patients.

Financial disclaimer None.

\section{Conflicts of interest None.}

Open Access This article is distributed under the terms of the Creative Commons Attribution Noncommercial License which permits any noncommercial use, distribution, and reproduction in any medium, provided the original author(s) and source are credited.

\section{References}

1. Swift S, Woodman P, O'Boyle A et al (2005) Pelvic Organ Support Study (POSST): the distribution, clinical definition, and epidemiologic condition of pelvic organ support defects. Am J Obstet Gynecol 192(3):795-806

2. Jackson SR, Avery NC, Tarlton JF, Eckford SD, Abrams P, Bailey AJ (1996) Changes in metabolism of collagen in genitourinary prolapse. Lancet 347(9016):1658-1661

3. Kerkhof MH, Hendriks L, Brölmann HA (2009) Changes in connective tissue in patients with pelvic organ prolapse - a review of the current literature. Int Urogynecol J Pelvic Floor Dysfunct 20(4):461-474

4. Malfait F, De Paepe A (2005) Molecular genetics in classic Ehlers-Danlos syndrome. Am J Med Genet C Semin Med Genet 139C(1):17-23

5. Callewaert B, Malfait F, Loeys B, De Paepe A (2008) EhlersDanlos syndromes and Marfan syndrome. Best Pract Res Clin Rheumatol 22(1):165-189

6. Carley ME, Schaffer J (2000) Urinary incontinence and pelvic organ prolapse in women with Marfan or Ehlers Danlos syndrome. Am J Obstet Gynecol 182(5):1021-1023

7. Meyer AL, Berger E, Monteiro O Jr, Alonso PA, Stavale JN, Gonçalves MP (2007) Quantitative and qualitative analysis of 
collagen types in the fascia transversalis of inguinal hernia patients. Arq Gastorenterol 44(3):230-234

8. Casanova AB, Trindade EN, Trindade MR (2009) Collagen in the transversalis fascia of patients with indirect inguinal hernia: a case-control study. Am J Surg 198(1):1-5

9. Ozdogan M, Yildiz F, Gurer A, Orhun S, Kulocoglu H, Aydin R (2006) Changes in collagen and elastic fiber contents of the skin, rectus sheath, transversalis fascia and peritoneum in primary inguinal hernia patients. Bratisl Lek Listy 107(6-7):235-238

10. Friedman DW, Boyd CD, Norton P et al (1993) Increases in type III collagen gene expression and protein synthesis in patients with inguinal hernias. Ann Surg 218(6):754-760

11. Haviarova Z, Janega P, Durdik S, Kovac P, Mraz P, Stvrtinova V (2008) Comparison of collagen subtype I and III presence in varicose and non-varicose vein walls. Bratisl Lek Listy 109(3):102-105

12. Sansilvestri-Morel P, Rupin A, Badier-Commander C et al (2001) Imbalance in the synthesis of collagen type I and collagen type III in smooth muscle cells derived from human varicose veins. J Vasc Res 38(6):560-568

13. Lim CS, Davies AH (2009) Pathogenesis of primary varicose veins. Br J Surg 96(11):1231-1242

14. Carmo M, Colombo L, Bruno A et al (2002) Alteration of elastin, collagen and their cross-links in abdominal aortic aneurysms. Eur J Vasc Endovasc Surg 23(6):543-549

15. Malfait F, Hakim AJ, De Paepe A, Grahame R (2006) The genetic basis of the joint hypermobility syndromes. Rheumatology 45 (5):502-507

16. Miedel A, Tegerstedt G, Maehle-Schmidt M, Nyrén O, Hammerström M (2009) Nonobstetric risk factors for symptomatic pelvic organ prolapse. Obstet Gynecol 113(5):1089-1097

17. Rosch R, Junge K, Knops M, Lynen P, Klinge U, Schumpelick V (2003) Analysis of collagen-interacting proteins in patients with incisional hernias. Langenbecks Arch Surg 387(11-12):427-432

18. Raffetto JD, Cheung Y, Fisher JB et al (2003) Incision and abdominal wall hernias in patients with aneurysm or occlusive aortic disease. J Vasc Surg 37(6):1150-1154

19. Norton PA, Baker JE, Sharp HC, Warenski JC (1995) Genitourinary prolapse and joint hypermobility in women. Obstet Gynecol 85 (2):225-228

20. Aydeniz A, Dikensoy E, Cebesoy B, Altindağ O, Gürsoy S, Balat O (2010) The relation between genitourinary prolapse and joint hypermobility in Turkish women. Arch Gynecol Obstet 281 (2):301-304
21. Bai SW, Choe BH, Kim JY, Park KH (2002) Pelvic organ prolapse and connective tissue abnormalities in Korean women. J Reprod Med 47(3):231-234

22. Spath MA, Feuth TB, Smits APT et al (2011) Predictors and risk model development for menopausal age in fragile $\times$ premutation carriers. Genet Med 13(7):643-650

23. Bump RC, Mattiasson A, Bǿ K et al (1996) The standardization of terminology of female pelvic organ prolapse and pelvic floor dysfunction. Am J Obstet Gynecol 175(1):10-17

24. Chiaffarino F, Chatenoud L, Dindelli M et al (1999) Reproductive factors, family history, occupation and risk of urogenital prolapse. Eur J Obstet Gynecol Reprod Biol 82(1):63-67

25. McLennan MT, Harris JK, Kariuki B, Meyer S (2008) Family history as a risk factor for pelvic organ prolapse. Int Urogynecol J Pelvic Floor Dysfunct 19(8):1063-1069

26. Twiss C, Triaca V, Rodríguez LV (2007) Familial transmission of urogenital prolapse and incontinence. Curr Opin Obstet Gynecol 19(5):464-468

27. Buchsbaum GM, Duecy EE, Kerr LA, Huang LS, Perevich M, Guzick DS (2006) Pelvic organ prolapse in nulliparous women and their parous sisters. Obstet Gynecol 108(6):1388-1393

28. Jack GS, Nikolova G, Vilain E, Raz S, Rodríguez LV (2006) Familial transmission of genitovaginal prolapse. Int Urogynecol J Pelvic Floor Dysfunct 17(5):498-501

29. Altman D, Forsman M, Falconer C, Lichtenstein P (2008) Genetic influence on stress urinary incontinence and pelvic organ prolapse. Eur Urol 54(4):918-922

30. Al-Rawi ZS, Al-Rawi ZT (1982) Joint hypermobility in women with genital prolapse. Lancet 1(8287):1439-1441

31. Hansell NK, Dietz HP, Treloar SA, Clarke B, Martin NG (2004) Genitic covariation of pelvic organ and elbow mobility in twins and their sisters. Twin Res 7(3):254-260

32. Knuuti E, Kauppila S, Kotila V, Risteli J, Nissi R (2011) Genitourinary prolapse and joint hypermobility are associated with altered type I and III collagen metabolism. Arch Gynecol Obstet 283(5):1081-1085

33. Kluivers KB, Dijkstra JR, Hendriks JC, Lince SL, Vierhout ME, van Kempen LC (2009) COL3A1 2209G $>A$ is a predictor of pelvic organ prolapse. Int Urogynecol J Pelvic Floor Dysfunct 20(9):1113-1118

34. Rodrigues AM, Girão MJ, da Silva ID, Sartori MG, Martins Kde F, Castro Rde A (2008) COL1A1 Sp1-binding site polymorphism as a risk factor for genital prolapse. Int Urogynecol J Pelvic Floor Dysfunct 19(11):1471-1475 